\title{
Vasopressor therapy in atypical antipsychotic overdose
}

\author{
V Pillay-Fuentes Lorente, ${ }^{1}$ MB ChB, PG Dip (Med Dev); R van Rensburg, ${ }^{1}$ MB ChB, Dip HIV Man (SA); D A Cloete, ${ }^{2}$ MB ChB, MSc PEM \\ (Edin), Dip HIV Man (SA); S Lahri, ${ }^{2}$ MB ChB, FCEM (SA); E H Decloedt, ${ }^{1}$ MB ChB, BSc Hons, FCCP (SA), MMed (Clin Pharm), PhD \\ ${ }^{1}$ Division of Clinical Pharmacology, Department of Medicine, Faculty of Medicine and Health Sciences, Stellenbosch University, Cape Town, \\ South Africa \\ ${ }^{2}$ Division of Emergency Medicine, Department of Family Medicine, Faculty of Medicine and Health Sciences, Stellenbosch University, Cape Town, \\ South Africa
}

Corresponding author: V Pillay-Fuentes Lorente (14847795@sun.ac.za)

\begin{abstract}
Hypotension is a common presentation following an overdose of quetiapine. Adrenaline is often used as the vasopressor of choice for hypotension not responding to intravenous fluids. We present a case of quetiapine overdose with hypotension unresponsive to high-dose adrenaline. The patient was commenced on noradrenaline and made a full recovery. We highlight learning points about vasopressor therapy for atypical antipsychotic overdose. Quetiapine-induced hypotension is thought to be mediated by $\alpha_{1}$-receptor antagonism. Adrenaline is unlikely to improve blood pressure, as it is an agonist at both $\alpha$ - and $\beta$-receptors. Alpha-2- and $\beta_{2}$-agonism can reduce sympathetic outflow and cause vasodilation, respectively, further exacerbating the hypotension. Noradrenaline is the preferred vasopressor of choice for hypotension caused by quetiapine overdose, as it has less affinity for $\alpha_{2}$ - and $\beta_{2}$-receptors, but maintains $\alpha_{1}$-receptor agonism. Drugs with a similar mechanism of inducing hypotension should also be treated with noradrenaline as the vasopressor of choice.
\end{abstract}

S Afr Med J 2020;110(10):1003-1005. https://doi.org/10.7196/SAMJ.2020.v110i10.14771

Mortality due to intentional self-harm in South Africa (SA) constitutes $0.1 \%$ of all-cause mortality and $0.8 \%$ of non-natural deaths. ${ }^{[1]}$ Data on admissions to intensive care units (ICUs) in SA following overdose (OD) are sparse. A 2014 study conducted at Frere Hospital in East London, SA, found that $5.6 \%$ of ICU admissions were related to OD, constituting $25 \%$ of all medically related ICU admissions. ${ }^{[2]}$ An Australian study reported an ICU admission rate between $13 \%$ and $22 \%$ following an $\mathrm{OD} .{ }^{[3]}$ In the USA, $1 \%$ of emergency admissions are due to drug OD, with $\sim 25 \%$ of these patients requiring ICU admission. ${ }^{[4]}$ In the 2018 Annual Report of the American Association of Poison Control Centers' National Poison Data System, antipsychotics remain the second-largest class of drugs - after analgesics - involved in ODs in adults. ${ }^{[5]}$

Atypical antipsychotics such as quetiapine, olanzapine, clozapine and risperidone exert antagonism at serotonin and dopamine receptors, warranting their use in bipolar disorder and schizophrenia. ${ }^{[6]}$ In addition, they display off-target binding to $\alpha_{1}$-adrenergic receptors that may lead to vasodilation and lowered blood pressure. ${ }^{[6]}$ Quetiapine has a greater preponderance to cause hypotension than most antipsychotics. ${ }^{[7]} \mathrm{A}$ systematic review of cardiovascular toxicity associated with atypical antipsychotic OD noted tachycardia, hypotension and prolonged QRS intervals as common presentations, with hypotension recorded in up to $42 \%$ of patients presenting with an OD of quetiapine only. ${ }^{[8]}$ Deaths from quetiapine $\mathrm{OD}$ were estimated to be in the range of 31.3 per million prescriptions in England and Wales between 1993 and 2002. ${ }^{[9]}$ A more recent analysis in Australia between 2006 and 2016 estimated death as a direct consequence of quetiapine OD to be $\sim 1.2 \%$ in cases where quetiapine was detected post mortem. ${ }^{[10]}$ Quetiapine was also implicated as contributory to death in $37.4 \%$ of polypharmacy ODs in the same analysis. ${ }^{[10]}$ Although some international data are available, there remains a paucity of data on quetiapine OD in the SA setting. Hypotension is a common and often challenging presentation in patients who have taken an OD of commonly prescribed medications such as antipsychotics, tricyclic antidepressants, beta-blockers or calcium channel blockers. ${ }^{[1]}$ In an SA study, hypotension was reported as a frequent indication for ICU admission in tricyclic antidepressant OD. ${ }^{[12]}$ Haemodynamic monitoring has been recorded as the second most common reason for ICU admission following a depressed level of consciousness requiring intubation. ${ }^{[13]}$ Previous reports have advocated against the use of adrenaline to manage hypotension resistant to intravenous fluids (IVF) in quetiapine OD. ${ }^{[7,14]}$ By virtue of its mechanism of action, adrenaline use in the setting of quetiapine OD further lowers the blood pressure. ${ }^{[14]}$ Adrenaline is a readily available and costeffective vasopressor included in the essential medicines list for SA. However, adrenaline may not be an effective or pharmacologically appropriate vasopressor in all cases of OD-associated hypotension. We report a case of a patient who took an OD of quetiapine, an atypical antipsychotic, and presented with significant hypotension unresponsive to adrenaline.

\section{Case report}

A 19-year-old woman was brought to the emergency unit by her relatives, following a reported OD of an unknown amount of her prescription quetiapine tablets. Her notable past medical history included major depressive disorder, generalised anxiety disorder with borderline personality traits, and regular cannabis use. No co-ingestants were reported.

On initial assessment, her vital signs were within normal limits: blood pressure (BP) 116/69 $\mathrm{mmHg}$, heart rate $70 \mathrm{bpm}$, afebrile, respiratory rate 20 breaths per minute, and oxygen saturation $97 \%$ on room air. However, owing to her depressed level of consciousness (Glasgow Coma Scale 7/15) and subsequent inability to protect her airway, rapid-sequence intubation was performed with succinylcholine and ketamine. Her electrocardiogram showed sinus tachycardia only, with no other abnormalities such as a prolonged QT interval or a widened QRS complex. Her baseline blood results (full 
blood count, liver function tests, glucose, and urea, creatinine and electrolytes) were unremarkable.

Six hours after ingestion, the patient developed hypotension with BP 76/37 mmHg and mean arterial pressure (MAP) $50 \mathrm{mmHg}$. The treating doctor initiated an adrenaline infusion: $20 \mathrm{mg}$ of 1:1 000 adrenaline diluted in $200 \mathrm{~mL}$ normal saline, running at $10 \mathrm{~mL} / \mathrm{h}^{[15]}$ The infusion was titrated up to $28 \mathrm{~mL} / \mathrm{h}$ in an attempt to improve her BP, which did not increase above $84 / 45 \mathrm{mmHg}$ with MAP $58 \mathrm{mmHg}$. The Poisons Information Helpline of the Western Cape was contacted regarding the next appropriate management steps, and advised the attending clinician to commence noradrenaline as the preferred vasopressor of choice in quetiapine OD. The patient's BP subsequently increased to $98 / 42 \mathrm{mmHg}$ with MAP $64 \mathrm{mmHg}$. She remained stable with MAP $>60 \mathrm{mmHg}$. Noradrenaline was weaned and eventually stopped 28 hours after initiation. The patient was extubated shortly thereafter and made a full recovery.

\section{Discussion}

In the case presented, our patient had profound hypotension following quetiapine OD. There was inadequate blood pressure response on adrenaline. After commencement of noradrenaline, the blood pressure improved significantly and the patient made a full recovery.

Quetiapine is an atypical antipsychotic drug. It is primarily an antagonist of $5 \mathrm{HT}_{2^{-}}$and $\mathrm{D}_{2}$-receptors, where it produces its antipsychotic and mood-stabilising effects. ${ }^{[16]}$ It also has antagonistic effects on histamine $\left(\mathrm{H}_{1}\right)$ and adrenergic $\left(\alpha_{1}\right.$ and $\left.\alpha_{2}\right)$ receptors, although it has a higher potency at $\alpha_{1}$ - than $\alpha_{2}$-receptors. ${ }^{[16]}$ Potent antagonism of $\alpha_{1}$-receptors is purported to cause the hypotension seen in OD. ${ }^{[16]}$ Quetiapine in OD is also more likely than the other atypical antipsychotics to produce significant clinical effects such as coma, respiratory depression or hypotension. ${ }^{[17]}$

The incidence of hypotension may be as high as $18 \%$ in patients with quetiapine $\mathrm{OD},{ }^{[17]}$ and pharmacological management begins with the administration of IVF, followed by vasopressors if IVF fails. ${ }^{[18]}$ In the SA context, adrenaline is frequently used as the first-line vasopressor of choice by attending doctors. However, in quetiapine OD, noradrenaline is recommended as the vasopressor of choice in the management of hypotension. ${ }^{[14]}$ The rationale for the preference of noradrenaline over adrenaline in managing such patients is based primarily on their receptor propensities. Adrenaline has both $\beta_{1}$ - and $\beta_{2}$-receptor agonist activity in addition to its $\alpha_{1}$ - and $\alpha_{2}$-receptor agonism. ${ }^{[19]}$ Quetiapine OD causes hypotension by potent antagonism of $\alpha_{1}$-receptors, with adrenaline displaying suboptimal vasoconstriction owing to not fully displacing quetiapine from the $\alpha_{1}$-receptor. The simultaneous stimulation of presynaptic $\alpha_{2}$-receptors in addition to $\beta_{2}$-receptors by adrenaline reduce sympathetic outflow by decreasing noradrenaline release from the sympathetic nerve endings, and paradoxical vascular smooth-muscle relaxation and vasodilation, respectively, ${ }^{[1,20]}$ thereby decreasing systemic vascular resistance and further lowering blood pressure. ${ }^{[20]}$ The net effect is that the hypotension is unlikely to improve and may even deteriorate following the administration of adrenaline in these patients. In comparison with adrenaline, noradrenaline has potent $\alpha_{1}$-agonist activity and less affinity for $\beta_{2}$-receptors. ${ }^{[21]}$ The vasoconstriction mediated by noradrenaline ( $\alpha_{1}$-agonism) is therefore not counteracted by peripheral vasodilatation ( $\beta_{2}$-agonism), and the adverse effect of a quetiapine OD on blood pressure is not augmented. ${ }^{[14,22]}$

Other atypical antipsychotics commonly used in SA, such as olanzapine, clozapine and risperidone, may cause hypotension in OD. Similar to quetiapine, olanzapine, clozapine and risperidone mediate hypotension by $\alpha_{1}$-adrenergic antagonism. ${ }^{[23]}$ The use of vasopressors with $\beta_{2}$-receptor agonism could therefore also result in refractory hypotension. Tricyclic antidepressants (TCAs) may also cause hypotension in OD by $\alpha_{1}$-adrenergic antagonism, and therefore noradrenaline may likewise be a more appropriate alternative in these patients. ${ }^{[24,25]}$ Noradrenaline has also been shown to be a better vasopressor than dopamine in TCA-induced hypotension. ${ }^{[25]}$ Dopamine exerts some of its effects through the release of catecholamines, which may be depleted in OD states. ${ }^{[26]}$ It may therefore not be a suitable drug to treat refractory hypotension in these ODs. On the contrary, in beta-blocker OD, unopposed $\beta$ - or $\alpha$-receptor stimulation is potentially hazardous, and adrenaline is the preferred drug of choice as it possesses both $\alpha$ - and $\beta$-receptor agonism. ${ }^{[26]}$ Noradrenaline is currently only accessible via Section 21 approval in SA. Selected hospitals should consider having limited stock available to facilitate prompt access to noradrenaline in cases of significant quetiapine OD.

\section{Conclusions}

Drug ODs are common presentations to emergency units globally, and SA is no exception. Knowledge of the specific mechanisms of action of these drugs, as well as those of the vasopressors available to the attending doctor, is of paramount importance and will ensure the appropriate selection of vasopressors when indicated and mitigate potential iatrogenic complications. While adrenaline is often the first-line vasopressor in hypotension not responding to IVF, the recommended vasopressor of choice for quetiapine OD is noradrenaline.

\section{Teaching points}

- Quetiapine OD commonly presents with hypotension as a result of $\alpha_{1}$-adrenergic receptor antagonism.

- Adrenaline is commonly used as a first-line vasopressor in hypotension unresponsive to IVF. However, in quetiapine OD, adrenaline may worsen blood pressure owing to presynaptic $\alpha_{2}$ and $\beta_{2}$-adrenergic receptor agonism, resulting in reduced sympathetic outflow and vasodilation, respectively.

- Noradrenaline is the preferred vasopressor in quetiapine OD owing to its potent agonism at $\alpha_{1}$-adrenergic receptors and negligible effects at $\alpha_{2}$ - and $\beta_{2}$-receptors.

- In SA, noradrenaline is accessed via Section 21 approval. Selected hospitals should consider having stock available to facilitate prompt access to noradrenaline in cases of significant quetiapine OD.

Declaration. None.

Acknowledgements. We thank the patient for consenting to the writing of this report.

Author contributions. All authors contributed to the writing of the manuscript.

Funding. None.

Conflicts of interest. None.

1. Statistics South Africa. Mortality and causes of death in South Africa, 2016: Findings from death notification. Statistical release P0309.3. Pretoria: Stats SA, 2019. http://www.statssa.gov.za/ publications/P03093/P030932016.pdf (accessed 18 February 2020).

2. Rowe K. The burden of drug overdose on critical care units in East London, South Africa. S Afr Med J 2016;106(3):227-228. https://doi.org/10.7196/SAMJ.2016.v106i3.9933

3. Athavale V, Green C, Lim KZ, et al. Characteristics and outcomes of patients with drug overdose requiring admission to intensive care unit. Australas Psychiatry 2017;25(5):489-493. https://doi. $\mathrm{org} / 10.1177 / 1039856217706824$

4. Schuring CA, Dodge DL, Whitcomb TJ, et al. Overdoses and substance toxicity in patients admitted to intensive care units in a midwestern U.S. city. J Trauma Nurs 2018;25(2):87-91. https://doi. org/10.1097/JTN.0000000000000349 
5. Gummin DD, Mowry JB, Spyker DA, et al. 2018 Annual Report of the American Association of Poison Control Centers' National Poison Data System (NPDS): 36th Annual Report. Clin Toxicol Poison Control Centers' National Poison Data System (NPDS): 36th

6. Minns AB, Clark RF. Toxicology and overdose of atypical antipsychotics. J Emerg Med 2012;43(5):906913. https://doi.org/10.1016/j.jemermed.2012.03.002

7. Trenton AJ, Currier GW, Zwemer FL. Fatalities associated with therapeutic use and overdose of atypical antipsychotics. CNS Drugs 2003;17(5):307-324. https://doi.org/10.2165/00023210-200317050-00002 8. Tan HH, Hoppe J, Heard K. A systematic review of cardiovascular effects after atypical antipsychotic medication overdose. Am J Emerg Med 2009;27(5):607-616. https://doi.org/10.1016/j.ajem.2008.04.020 9. Flanagan RJ. Fatal toxicity of drugs used in psychiatry. Hum Psychopharmacol Clin Exp 2008;23(S1):S43-S51. https://doi.org/10.1002/hup.916

10. Lee J, Pilgrim J, Gerostamoulos D, et al. Increasing rates of quetiapine overdose, misuse, and mortality in Victoria, Australia. Drug Alcohol Depend 2018;187:95-99. https://doi.org/10.1016/j. drugalcdep.2018.03.002

11. Byrd LB, Martin N. Antidotes. StatPearls Publishing, 2020. https://www.ncbi.nlm.nih.gov/books/ NBK539884/ (accessed 18 February 2020).

12. Koegelenberg CFN, Joubert ZJ, Irusen EM. Tricyclic antidepressant overdose necessitating ICU admission. S Afr Med J 2012:102(5):293-294.

13. Clark D, Murray DB, Ray D. Epidemiology and outcomes of patients admitted to critical care after selfpoisoning. J Intensive Care Soc 2011;12(4):268-273. https://doi.org/10.1177/175114371101200405 4. Hawkins DJ, Unwin P. Paradoxical and severe hypotension in response to adrenaline infusions in massive quetiapine overdose. Crit Care Resusc 2008;10(4):320-322.

15. National Department of Health, South Africa. Standard treatment guidelines and essential medicines list for South Africa: Hospital level, adults, 2019 edition. 2019. http://www.health.gov.za/index.php/ standard-treatment-guidelines-and-essential-medicines-list/category/286-hospital-level-adults (accessed 7 May 2020).

16. AstraZeneca. Highlights of prescribing information: Seroquel. 2016. https://www.accessdata.fda.gov/ drugsatfda_docs/label/2016/020639s064lbl.pdf (accessed 27 December 2019).

17. Ngo A, Ciranni M, Olson KR. Acute quetiapine overdose in adults: A 5-year retrospective case series. Ann Emerg Med 2008;52(5):541-547. https://doi.org/10.1016/j.annemergmed.2008.03.016
Ann
18. Gaieski DF, Mikkelsen ME. Evaluation of and initial approach to the adult patient with undifferentiated hypotension and shock. UpToDate. https://www-uptodate-com.ez.sun.ac.za/ undifferentiated hypotension and shock. UpToDate. https://wwW-uptodate-com.ez.sun.ac.za/
contents/evaluation-of-and-initial-approach-to-the-adult-patient-with-undifferentiatedcontents/evaluation-of-and-initial-approach-to-the-adult-patient-with-undifferentiated-
hypotension-and-shock?search=hypotension\% 20 management\&source=search_result\&selectedTitl hypotension-and-shock?search=hypotension\%20management\&source=search_result\&selec
$\mathrm{e}=2 \sim 150$ \&usage_type=default\&display_rank=2\#H87905475 (accessed 27 December 2019).

19. Brunton LL, Hilal-Dandan R, Knollmann BC, eds. Goodman \& Gilman's The Pharmacological Basis Brunton LL, Hilal-Dandan R, Knollmann BC, eds. Goodman \& Gilm
of Therapeutics. 13th ed. New York: McGraw-Hill Education, 2018.

20. Overgaard $\mathrm{CB}$, Dzavík V. Inotropes and vasopressors: Review of physiology and clinical use in cardiovascular disease. Circulation 2008;118(10):1047-1056. https://doi.org/10.1161/ CIRCULATIONAHA.107.728840

21. Davis AL, Carcillo JA, Aneja RK, et al. The American College of Critical Care Medicine clinical practice parameters for hemodynamic support of pediatric and neonatal septic shock: Executive summary. Pediatr Crit Care Med 2017;18(9):884-890. https://doi.org/10.1097/ PCC. 0000000000001259

22. Allwood I, Allwood MJ, Cobbold AF, et al. Peripheral vascular effects. Br Med Bull 1963;19(1949):132136. https://doi.org/10.1093/oxfordjournals.bmb.a070031

23. Eli Lilly and Company. Highlights of prescribing information ZYPREXA. 2020. https://pi.lilly.com/ us/zyprexa-pi.pdf (accessed 1 May 2020)

24. Kerr GW, Mcguye AC, Wilkie S. Tricyclic antidepressant overdose: A review. Emerg Med J 2001;18(4):236-241. https://doi.org/10.1136/emj.18.4.236

25. Tran TP, Panacek EA, Rhee KJ, et al. Response to dopamine vs norepinephrine in tricyclic antidepressant-induced hypotension. Acad Emerg Med 1997;4(9):864-868. https://doi org/10.1111/j.1553-2712.1997.tb03811.x

26. Barsan W, Younger JG. Management of emergencies in critical care. Semin Respir Crit Care Med 2002;23(1):001-002. https://doi.org/10.1055/s-2002-2058

Accepted 26 May 2020 